\title{
Planning and managing primary care services: lessons from the NHS in England
}

\section{Kath Checkland, Imelda McDermott, Anna Coleman, Lynsey Warwick-Giles,} Donna Bramwell, Pauline Allen \& Stephen Peckham

To cite this article: Kath Checkland, Imelda McDermott, Anna Coleman, Lynsey Warwick-Giles, Donna Bramwell, Pauline Allen \& Stephen Peckham (2018) Planning and managing primary care services: lessons from the NHS in England, Public Money \& Management, 38:4, 261-270, DOI: 10.1080/09540962.2018.1449467

To link to this article: https://doi.org/10.1080/09540962.2018.1449467

册 Published online: 22 Mar 2018.

Submit your article to this journal $\sqsubset \pi$

Q View related articles $\sqsubset$

View Crossmark data $₫$ 


\section{Planning and managing primary care services: lessons from the NHS in England}

\section{Kath Checkland, Imelda McDermott, Anna Coleman, Lynsey Warwick-Giles, Donna Bramwell, Pauline Allen and Stephen Peckham}

High-quality primary care services are an essential part of a successful health service. However, the planning and management of such services is complex. Using evidence from a study of recent extensive changes in the English NHS, the authors highlight the need for local service oversight by managers who understand local conditions and needs. The recent English experience supports an incremental policy adjustment approach, rather than wholesale organizational change.

Keywords: Commissioning; complexity; path dependency; policy incrementalism; primary care.

It is generally agreed that access to high-quality primary care is vital in the quest to provide the best possible health care at the lowest cost (Starfield et al., 2005; World Health Organization, 2008). Finding new ways to deliver and extend access to primary care services is of high priority in many health systems (Schoen et al., 2007; Shortell et al., 2010). The UK is no exception, and the past 30 years has seen a wide range of initiatives focused on primary care-particularly services provided by primary care physicians: GPs. Some initiatives have focused on payment models, altering contracts in an effort to change behaviour (Heins et al., 2009; Gillam et al., 2012). Others have focused on the planning side, repeatedly enlarging, shrinking and reorganizing the organizations with responsibility for commissioning/purchasing primary care services on behalf of a population (Wilkin et al., 2004). In this paper we explore the latest of these policy and organizational changes, presenting the findings from an empirical study investigating recent changes to the commissioning of primary care services in England. Using an historical account of mechanisms to plan and manage GP services in England, we identify some of the issues involved. We explore the espoused logic underpinning the current reforms, and present early evidence about their implementation, highlighting the extent to which they may meet official aims and address the identified issues. The contribution offered is twofold:

- First, we offer an account of the development of planning and management of GP services in England, bringing clarity to a complex field and providing valuable evidence for those responsible for overseeing primary care services in the $\mathrm{UK}$ and internationally.

- Second, our exploration of the implementation of the latest round of reforms provides some lessons about the interplay between local, regional and national planning, and about the ways in which policy is made and implemented.

What follows is divided into five sections. An historical account of GP services in the UK is followed by a short description of recent NHS reforms in England. Study methods are then described, followed by results. A final section discusses our findings in context, and draws lessons for the English NHS and for primary care service provision more widely.

Planning and managing primary care services in England: an historical account The current primary care system in England arose out of the decision made at the establishment of the NHS in 1947 to allow GPs to be contractors to the NHS rather than employees. This enabled GPs to remain independent, minimizing their opposition to the NHS (Lewis, 1997; Peckham and Exworthy,
Kath Checkland is a Professor of Health Policy E Primary Care, Health Policy, Politics E

Organisation

Research Group

(HiPPO), Centre for

Primary Care,

University of

Manchester, UK.

Imelda McDermott is a Research Fellow at HiPPO, University of Manchester, UK.

Anna Coleman is a Senior Research Fellow at HiPPO, University of Manchester, UK.

Lynsey WarwickGiles is a Research Associate at HiPPO, University of Manchester, UK.

Donna Bramwell is an Honorary

Research Associate at 
HiPPO, University of Manchester, UK.

Pauline Allen is a Professor of Health Services

Organisation and

Head of the

Department of

Health Services

Research and Policy,

London School of

Hygiene E Tropical

Medicine, $U K$.

Stephen Peckham is a Professor of Health Policy, Centre for

Health Services

Studies, University

of Kent, UK.
2003). Treatment in primary care is free at the point of use, apart from a small number of copayments (for example a prescription charge). From 1948-1990, there was little local oversight of GP services, with payments governed by a manual setting out conditions for payment. This represented the accretion over time of regulations and payments which were nationally set. The distribution of GPs was decided by the Medical Practices Committee-a national nondepartmental public body. This committee was responsible for giving permission for the setting up of new practices, with those areas of the country deemed to have sufficient coverage said to be 'closed'. There was little active planning to ensure population coverage, and no local oversight.

In 1990, the Conservative government imposed a new GP contract (Hannay et al., 1992), known as the 'general medical services' contract, GMS. It introduced two elements: target payments for some services such as vaccinations; and payment for delivering specific services, such as pro-active care for chronic diseases. This introduced some elements of local control into the system, with local 'family health service authorities' responsible for accrediting GP-run chronic disease clinics and for administering resulting payments. By the end of the 1990s, GP morale was low (Sibbald et al., 2003), and a new contract was negotiated between the Department of Health and the British Medical Association (the GPs' representative body).

The resulting 2004 new national GMS contract has been comprehensibly described elsewhere (Lewis and Gillam, 2002). It combined a basic payment (calculated by a formula) with additional payments for meeting quality thresholds (the quality and outcomes framework, QOF) and for providing a range of additional services known as 'enhanced services'. Crucially, local management authorities (soon known as 'primary care trusts', PCTs) had the discretion to develop local service schemes in the community to replace or supplement secondary care services. Alongside the nationally negotiated GMS contract, PCTs had local flexibility in two additional contract types: personal medical services (PMS); and alternative providers of medical services (APMS). PMS contracts theoretically allowed local management authorities to negotiate specific contracts with GP practices. These were intended to increase flexibility, allowing, for example, specific services to be commissioned for hard to reach populations and enabling the greater performance management of practices
(Campbell et al., 2005). In practice, PMS contracts, once negotiated, were not policed, and they tended to act to entrench income inequalities between practices (Majeed et al., 2012). APMS contracts were available for 'nontraditional' providers of primary care, including private companies. They were introduced in 2004 to encourage the setting up of new practices in 'under-doctored' areas (Department of Health, 2006). They were the preferred means of procuring additional GP services throughout the 2000s, and in part their use was intended to increase competitive pressures on traditional GP practices (Coleman et al., 2013).

Thus, through the 2000s, policy focused on introducing mechanisms to support the local planning and quality improvement of primary care services. However, freedom remained constrained by the national negotiation of the base contract, which accounted for the major proportion of practice income. Flexibilities focused on additional 'enhanced' services, and on procuring new practices via APMS contracts.

This brief historical account has highlighted some of the issues associated with planning and managing primary care services. Two issues stand out. First, primary care in England is a system which exhibits 'path dependency' (David, 1985; Tuohy, 1999). The initial establishment of GPs as independent contractors to the NHS has been resilient in the face of change, leading to the current patchwork of contract types and add on payments. Each new policy iteration has incrementally adjusted this system, with new policies addressing particular problems rather than taking an overview of the whole system. This fits with Lindblom's classic description of policy as 'muddling through' (Lindblom, 1959), advancing via small, step-by-step changes (Lindblom, 1979). Lindblom argues that such incremental change is indeed desirable (Lindblom, 1959), identifying with what Simon later called 'bounded rationality' (Simon, 1984), and arguing that: 'complex problems cannot be completely analysed, and we therefore need strategies for skilful incompleteness' (Lindblom, 1979, p. 524).

Second, since 1990, the English NHS has combined local responsibility for planning with national responsibility for payment mechanisms and amounts, with local planners only able to shift resources at the margins. Changes at these margins may have some impact (Checkland et al., 2011), but room for local financial manoeuvre has historically been limited. This 
has left local planners with few levers with which to enact change, and in their absence, local relationships and an understanding of the history that these reflect become increasingly important (Best et al., 2012).

\section{The commissioning of primary care services since 2010}

In 2010, the Coalition government introduced an extensive reform of the NHS (Timmins, 2012). The driver for the changes was a desire to bring GPs more closely into the commissioning of hospital services. It was claimed that front-line clinicians would be 'liberated' from managerial control (Department of Health, 2010), and thus able to improve quality of services. The Health and Social Care Act 2012 (HSCA12) created new commissioning organizations, known as clinical commissioning groups (CCGs), replacing PCTs. These were constituted as 'membership' organizations, with local GP practices as members (Checkland et al., 2013). Hence, it was argued that, while CCGs would take on responsibility for commissioning most health care services, it would be inappropriate for them to commission primary care services, because of the associated potential conflicts of interest (Department of Health, 2010). It was also argued that local variations in funding and services required a more standardized national approach to commissioning primary care (NHS Commissioning Board, 2012). Responsibility for this was therefore given to a new national organization, NHS England (known as the NHS Commissioning Board in statute), with these commissioning functions discharged by staff working in local area teams'. NHS England would thus combine a consistent and standardized national approach with appropriate local flexibility:

Having a consistent approach will also help us tackle unwarranted variation and take positive steps towards raising the overall standard of primary care provision to the level of the best.... However, the Government's vision is for decisions about services to be made as locally as possible, involving the people who use them as much as possible...By informing the national approach with the views and experiences of those commissioning and providing primary care services and those receiving care, we will ensure local implementation feels both relevant and owned by those delivering it (NHS Commissioning Board, 2012, p. 4).

This situation did not last long. In October
2014, it was announced that NHS England would be cutting staff and merging local area teams into four regional teams, covering large geographical areas (West and Calkin, 2014). This effectively ended the possibility of 'effective local relationships' (NHS Commissioning Board, 2012, p. 10) between primary care providers and NHS England commissioners, with smaller numbers of NHS England staff covering large geographical areas.

At around the same time, NHS England issued a 'Call to action', suggesting the need for more CCG involvement in commissioning primary care services. On 1 May 2014, the head of NHS England, Simon Stevens, announced that CCGs would get 'new powers' under a new commissioning initiative ("cocommissioning') and asked CCGs to consider the additional responsibilities they would like to assume. A letter to CCGs set out the issues:

If we want to better integrate care outside hospitals, and properly resource primary, community and mental health services - at a time when overall funding is inevitably constrained - we need to make it easier for patients, local communities and local clinicians to exercise more clout over how services are developed. That means giving local CCGs greater influence over the way NHS funding is being invested for their local populations... So today I am inviting those CCGs that are interested in an expanded role in primary care to come forward and show how new powers would enable them to drive up the quality of care, cut health inequalities in primary care, and help put their local NHS on a sustainable path for the next five years and beyond (Roughton and Hakin, 2014, p. 6).

Thus, the 'problem' to be solved was couched in terms of a need for greater local influence over service development. The need for standardization no longer figured, and it was argued that CCGs needed the opportunity to invest in local services. Importantly, there was to be no associated legislative change; statutory responsibility for commissioning primary care services remains with NHS England.

To return to the issues highlighted in our historical review, recent developments represent a further example of incremental policy adjustment, albeit within a very short timescale-the new approach was announced less than a year after the HSCA12 changes were enacted. Furthermore, the new arrangements are a move back towards a local model of service planning, with an attenuation of the role of national organizations. 
Against this background, we undertook an early study of the development of primary care co-commissioning by CCGs (McDermott et al., 2016). The focus of the study was:

- To explore the rationale underlying the delegation of commissioning responsibility to CCGs;

- To explore the early experiences of CCGs developing their plans for the commissioning of primary care services.

In the following sections we report the findings from our study, returning in the discussion to the issues surrounding the planning and management of GP services identified in the historical review above, asking: what can we learn from the recent experience of changes to primary care service planning in the English NHS?

\section{Methods}

The study included three elements: analysis of relevant policy documents; interviews with senior policy-makers; and a telephone survey of senior leaders from a sample of CCGs.

We obtained the published policy guidance relating to primary care co-commissioning (NHS England, 2014a; 2014b; 2014c; 2015), and analysed these to understand the 'programme theories' (Weiss, 1998) underlying the policy. Often implicit rather than explicit, programme theories represent the causal assumptions underlying policy. They embody official expectations as to how proffered policy solutions will alleviate or ameliorate identified policy problems. In the documents we reviewed it was argued that:

- Primary care needs to change to meet demographic challenges.

- CCG control over the primary care budget will enable transfer of resources from secondary care into primary care.

- $\mathrm{CCG}$ commissioning of primary care will support integrated care.

- CCGs will be able to invest in primary care, making it sustainable for the future (McDermott et al., 2016).

We tested these theories with senior policymakers by conducting six individual face-toface or telephone interviews with representatives of the organizations involved in co-commissioning policy, including: the Department of Health; NHS England; and NHS clinical commissioners. The interviews were carried out in June/July 2015. Interviewees were asked to explain what they thought the main 'problems' were with the commissioning of primary care services and to describe how the developing policy would address these. These interviews were transcribed and analysed, and the responses were compared with the programme theories above. Finally, we explored the early stages of policy implementation, by carrying out a telephone survey with 49 senior leaders from CCGs across levels of co-commissioning responsibility in summer 2015. These were purposively selected across a number of characteristics, including: levels of co-commissioning; all regions of England; a variety of CCGs' sizes; those involved in other service redesign initiatives; and both urban and rural CCGs (see table 1). Interviewees were asked to explain their aspirations for engaging with primary care co-commissioning, the factors underlying their choice of level of commissioning responsibility and their plans. Responses were tabulated in a spread-sheet for easy comparison. A full description of our methods can be found in the project report (McDermott et al., 2016).

\section{Results}

Primary care co-commissioning in theory: what is it intended to achieve?

Published guidance relating to primary care co-commissioning highlighted the need to bring together the commissioning of primary care services alongside other services, suggesting that separating the commissioning of different types of services had been counter-productive, preventing necessary integration:

The introduction of co-commissioning is an essential step towards expanding and strengthening primary medical care. Cocommissioning is recognition that clinical commissioning groups (CCGs) are harnessing clinical insight and energy to drive changes in their local health systems that have not been achievable before now, but are hindered from taking an holistic and integrated approach to improving healthcare for their local populations, due to their lack of say over both primary care and some specialized service (NHS England, 2014b, p. 4).

Interviews with policy-makers and senior managers confirmed this, suggesting that problems associated with the model put in place under the HSCA12 were obvious from the beginning:

...very early on, both in the year or so leading up 
to the formal change on 1st April 2013, and increasingly after April 2013, once CCGs were doing this for real, people started to say, this isn't really working, we get the theory of how CCGs could work alongside NHS England, but partly because NHS England has a much reduced primary care commissioning function, it feels rather remote from local communities, it's a very transactional form of commissioning. (Policymaker ID5.)

The move towards 'transactional commissioning' was mentioned by several interviewees. Rather than taking a strategic approach to service development and contract management, lack of capacity meant that NHS England teams were focused on making payments and checking that contract requirements had been met:

...part of the reason CCGs were so desperate to take on general practice commissioning was that in the two years NHS England had been doing it, almost nothing had happened. So the teams were too small, they were covering huge geographical areas, and they were purely doing contracting and making payments, there was no commissioning of primary care going on at all. (Policy-maker ID4.)

Importantly, the relational aspects of contracting which have been shown to be important in a publicly funded health system (Allen, 2002) were felt to be attenuated. For example staff who knew their local primary care providers were moved on or made redundant, and those remaining were felt to be remote:

The reality of NHS England regional teams is the capacity there is diminishing all the time and they are quite remote from the areas now. So there is very little to maintain that relationship between NHS England and practices. (Policy-maker ID1.)

Some interviewees went further, identifying many of the changes introduced by the HSCA12 as unhelpful, and suggesting that further policy change was needed:

Actually, I think co-commissioning was, if you like, almost like a sticky plaster to start trying to build that together and starting to replace some of what has been lost...I think the view of manymaybe not all-is that the Health and Social Care Act...certainly became a factor in terms of it fragmenting the commissioning of services, which meant that there was a step back from being able to develop a greater sense of, I suppose, local ownership and, indeed, a strategic overview of what, from a clinical perspective and from a local perspective, we wanted to achieve. (Policymaker ID1.)

The HSCA12 divided responsibilities for primary care, with so-called 'core' services being commissioned by NHS England, while 'enhanced' or additional services remained the responsibility of CCGs. In our historical review, we highlighted the fact that having a core national contract for the majority of primary

Table 1. Number of responses according to levels of co-commissioning responsibility and regions.

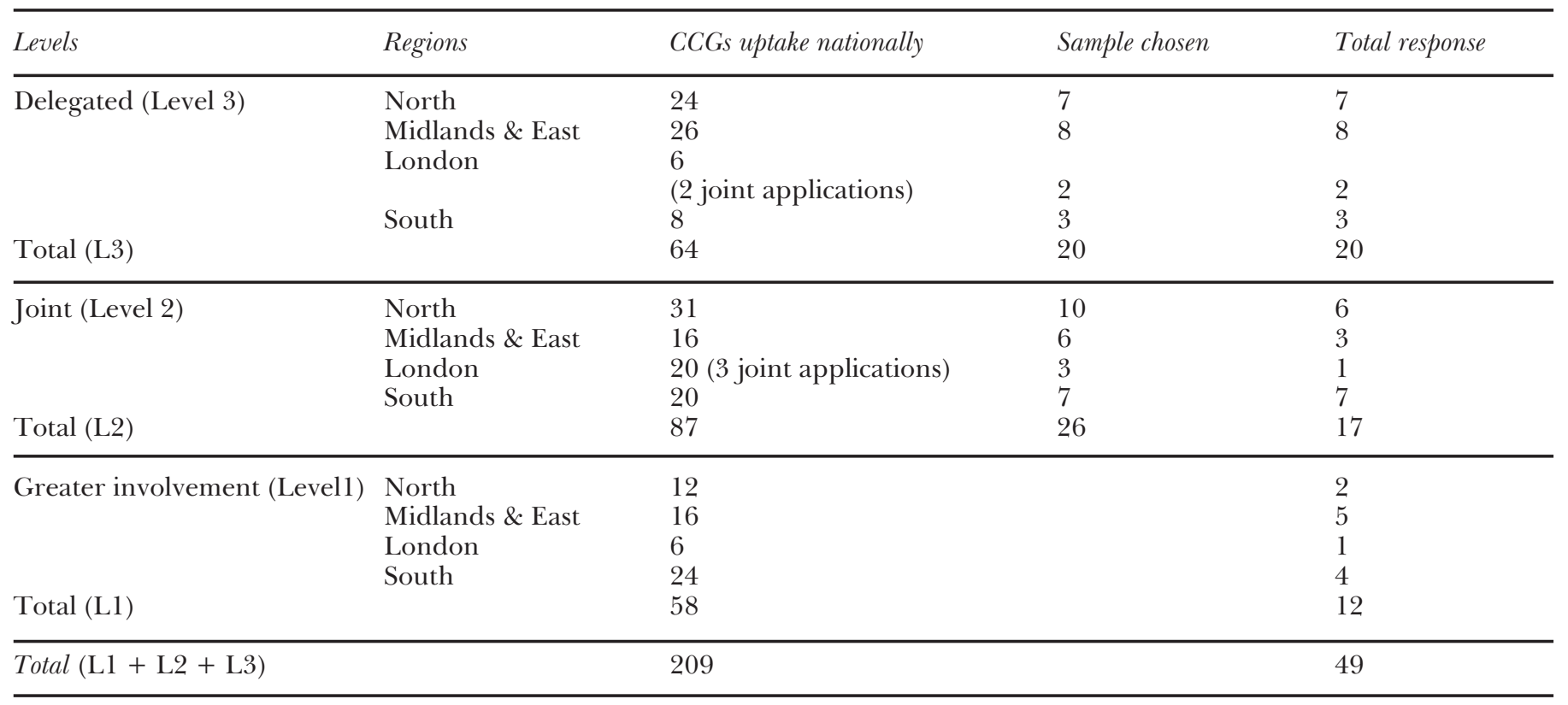


care services limits the capacity to be locally responsive. The various 'enhanced' service schemes developed over a number of years have been 'workarounds' to allow commissioners to invest in local services and give them some levers for change. However, as this senior policy actor highlights, sometimes what is required is simply more of the core services:

...we could always invest in enhanced services or different things, or extra things, but actually what we probablyneed is just more core (services), more people seeing more patients, and doing core general practice with them. (Policy-maker ID4.)

Other interviewees talked about moving towards a 'place-based' approach to commissioning services. This approach focuses on the services needed in a geographical area, aiming to integrate and remove the divisions between primary, secondary and community care:

So effectively what we've been doing over the last year is trying to reconnect some of the things that the 2012 Act disconnected. So there were a number of very good things in the Act, I think the clinically led CCG commissioning was an important step. But effectively what happened to commissioning was it got split into very different directions, so you had Public Health, bits of it going to local government, bits of it staying with NHS England, you then had primary care and specialist services with NHS England, the rest of healthcare commissioning with CCGs and local government social care commissioning somewhere else. And increasingly what we'd been saying... is what we need if we're going to act as effective agents for the public in local areas we need place based commissioning. So as far as possible let's try and mesh the money and let's try and link not just the various bits of the health service together but other parts of the public sector so that we can commission services in an integrated way and have trade-offs between different bits of the system. (Policy-maker ID2.)

However, doing this requires flexibility between funding streams, and ability to pool resources:

So, for a given population, there's a finite set of resources which is currently split a number of different ways. It's split between CCGs, NHS England and local authorities, most obviously...And place based commissioning, to my mind, is essentially about saying... we need to now allow local commissioners who understand the health needs of this population, to take a single view about how we best deploy that single set of resources to buy the best healthcare services, and produce the best health outcomes. (Policymaker ID5.)

Taken together, these accounts suggest a policy aiming to tackle many of the issues raised in our historical review. In particular, the need for locally-sensitive decision-making, and a desire to be able to shift resources between different types of services. However, other issues, such as the need to harmonize between the different contract types and, most notably, the problems associated with a national contract model which determines the majority of practice income, were left unaddressed.

Primary care co-commissioning in practice: what were CCGs intending to do?

Taking on responsibility for co-commissioning primary care was initially voluntary, with CCGs required to opt for one of three levels: fully delegated commissioning; joint commissioning, sharing responsibility with NHS England; and 'greater influence', with NHS England retaining most aspects of the role. The greatest number ofCCGs initially opted for 'joint' commissioning (87 out of 209 CCGs). However, it rapidly became clear that there was little difference between the levels, and that there was a policy intention that all CCGs would move quite quickly to take on full delegated responsibility.

In our telephone survey, participants were asked to explain their rationale for taking on responsibility for commissioning primary care. Their responses made it clear that one of the main problems that had been experienced following the HSCA12 had been the loss of local knowledge in the commissioning of primary care services. NHS England was felt to be remote, lacking the necessary understanding of local providers. We asked CCG leaders an open question as to the principle drivers underlying their adoption of the particular level of responsibility they had chosen. Of the 37 interviewees from CCGs opting to take delegated responsibility, 20 highlighted the opportunity to bring back local knowledge and control into the commissioning process as one of their most important drivers. They cited: knowledge about local practices' performance and capabilities; understanding of issues related to premises; and awareness of the needs of their local populations as being important. Two suggested that they felt they had "no choice' but to take on responsibility, while others referred to a variety of drivers such as an 
opportunity to develop better relationships with their member practices and an ability to look holistically at the primary care services. When asked about the benefits which might accrue from their new responsibilities, a number of interviewees argued that they would be in a better position to performance manage their practices than NHS England. In contrast to the senior policy-makers, only one interviewee mentioned the ability to implement new models of care, and one explicitly mentioned 'placebased' approaches to care.

When asked about their areas of focus, most described plans to streamline the additional funding streams flowing into general practice. As highlighted in our historical review, the funding of general practice in the $\mathrm{UK}$ is extremely complicated, with the three national contracts 'topped up' by a variety of 'enhanced' services. Those interviewed expressed an appetite to streamline these, while at the same time addressing historical funding discrepancies which had entered the system in the 1990s when PMS contracts were introduced. This was acknowledged as being a difficult task, with some explaining that practices in their area might lose considerable amounts of funding. However, in managing these difficult issues, they again cited their local knowledge and understanding as being an important asset.

This focus on local knowledge and understanding of local services fits with what is known in the wider literature relating to implementing service changes. Best et al. (2012) reviewed 84 studies of change within health care systems, and distilled from these five 'simple rules', including a need to 'attend to history'. They draw attention to the fact that 'history' does not only include knowledge of what has happened before, but also requires understanding of local social processes and the local norms and values underpinning service delivery (Best et al., 2012 p. 439). Our interviewees suggested that such deep contextual understanding was vital in ensuring that services adapted to meet changing patient needs.

Finally, when asked about problems and concerns regarding the process of taking on responsibility for the commissioning of primary care services, our interviewees highlighted three main issues. First, there was concern about resources. This encompassed both the availability of resources to invest in primary care services, and the managerial resources they needed to undertake the work required. CCGs have taken on responsibility for cocommissioning without any additional managerial funding, and this is a concern for many. Second, CCGs were concerned about their relationship with member practices. CCGs are constituted as membership organizations, and are therefore effectively commissioning and policing themselves. There is considerable scope for conflicts of interest, and concern that they may alienate their members as they, for example, withdraw funding from PMS practices. Finally, responsibility for commissioning primary care services has been delegated to CCGs without any change in legislation. This means that NHS England retains statutory responsibility, even though day-to-day responsibility is delegated to CCGs. This had caused problems for some CCGs during the handover, particularly those small CCGs that wished to work in collaboration with their neighbours. Some CCGs told us that they felt that the guidance surrounding the transfer of responsibilities was late to be issued, with a sense that NHS England had to react to issues as they arose rather than having a clear plan.

\section{Discussion}

The recent history of the commissioning of primary care services in England since 2010 resonates strongly with Lindblom's call for 'skilful incompleteness' in policy analysis and design (Lindblom, 1979, p. 524). The HSCA12 attempted a wholesale redesign of the English NHS, specifying, reorganizing and legislating for all aspects of the system (Timmins, 2012). The rapid need (after only a year) to revisit one of the elements of NHS services (i.e. primary care) suggests that this attempt at completeness had fallen short. The resulting changehanding responsibility for primary care planning back to local level-appears to represent a return to the dominant model of primary care policy development identified in our historical review: incremental adjustment to meet specific issues or concerns, as Lindblom advocated. However, the legislative legacy of the HSCA12 remains, with some evidence of problems associated with the staffing and statutory responsibilities associated with the commissioning of primary care services, as well as continuing concerns about potential conflicts of interest. Furthermore, the legacy and path dependence (David, 1985) arising out of the initial NHS establishment of GPs as independent contractors also remains in the complex patchwork of contracts and payment models.

What can be learnt from this experience that is of relevance to the planning and management of primary care services more 
generally? First, our findings chime with the view of major system change seen through a complexity lens. Complexity scientists argue that reorganizations affecting complex systems will result in unpredictable and emergent changes (Anderson and McDaniel, 2000; Plsek and Greenhalgh, 2001). While this may seem self-evident, it reinforces Lindblom's call for cautious and incremental policy change rather than wholesale reorganization. Our findings speak to the impossibility of foreseeing and pre-emptively managing all of the consequences of such a reorganization, and suggest that those responsible for health systems elsewhere would be well advised to proceed cautiously and incrementally as they seek to optimize system performance. Building in 'incompleteness' (Lindblom, 1979, p. 524), rather than seeking tidy legislative closure may be beneficial.

Second, our analysis of the post 2010 policy context makes it clear that the changes to primary care enacted by the HSCA12 were largely driven by two things:

- A desire for consistency and end to 'unwarranted variation'.

-The negative drive to avoid conflicts of interest.

Local responsiveness was to be delivered by a local function within the new national body, NHS England, but this was quickly lost in an early reorganization and reduction in staffing. Our respondents - at local and policy levelwere unanimous in highlighting the need for local oversight, contextual knowledge and good relationships in managing the realities of providing universal coverage of patient-facing services, and it would seem that this is an important lesson from the English experiment. Notwithstanding the desire for consistency in service availability and quality, strong local oversight, with sufficient managerial staff who possess the requisite contextual understanding of local services is essential.

Since 2014 there has been an explosion of new initiatives and pilots in the NHS in England, many designed to address some of the problems that we have highlighted. These include 'vanguards', which incentivize groups at different levels across the system to experiment with 'new models' of care (NHS England, 2016a). These are intended to pilot new forms of primary care contract, based on some form of capitation payment with incentives to improve population health and reduce use of expensive hospital services (Kaffash and Matthews-King, 2015). We have highlighted the path dependency embedded in the current system, with a complex web of core and 'addon' contractual arrangements having accrued over time. The new forms of contract proposed to support the development of new ways of working are intended to address this complexity, streamlining incentives and harmonizing services (NHS England, 2016a). However, in practice, primary care providers have not shown themselves to be eager to move from a complicated but familiar and predictable contract to one in which the potential rewards are unclear, and it is now suggested that the new contract might simply be a further add on (a 'virtual contract' (NHS England, 2016b, p. 20)) to the base contract. However this latest policy plays out, our study and the evidence relating to previous attempts to change contracts (Gillam et al., 2012) both suggest that there is clear potential for unintended consequences. Future research is needed not only to investigate the outcomes of any new contractual arrangements, but also to further explore how local contract management is best approached and how local imperatives interact with policy intentions.

\section{Acknowledgement}

This research was funded by the Policy Research Programme of the Department of Health. The views expressed are those of the researchers and not necessarily those of the Department of Health.

\section{References}

Allen, P. (2002), A socio-legal and economic analysis of contracting in the NHS internal market using a case study of contracting for district nursing. Social Science and Medicine, 54, 2, pp. 255-266.

Anderson, R. A. and McDaniel (Jr), R. R. (2000), Managing health care organizations: where professionalism meets complexity science. Health Care Management Review, 25, 1, p. 83.

Best, A., Greenhalgh, T., Lewis, S., Saul, J. E., Carroll, S. and Bitz, J. (2012), Large-system transformation in health care: a realist review. Milbank Quarterly, 90, 3, pp. 421-456.

Campbell, S., Steiner, A., Robison, J., Webb, D., Raven, A., Richards, S. and Roland, M. (2005), Do personal medical services contracts improve quality of care? A multi-method evaluation. Journal of Health Services Research \& Policy, 10, 1, pp. 31-39.

Checkland, K., Coleman, A. and Harrison, S. (2011), When is a saving not a saving? The micro-politics of budgets and savings under practice-based commissioning Public Money $\xi^{\circ}$ 
Management, 31, 4, pp. 241-248.

Checkland, K., Coleman, A., McDermott, I., Segar, J., Miller, R., Petsoulas, C., Wallace, A., Harrison, S. and Peckham, S. (2013), Primary care-led commissioning: applying lessons from the past to the early development of clinical commissioning groups in England. British Journal of General Practice, 63, 614, pp. e611e619.

Coleman, A., Checkland, K., McDermott, I. and Harrison, S. (2013), The limits of marketbased reforms in the NHS: the case of alternative providers in primary care. $B M C$ Health Services Research, 13 (Suppl. 1), S3.

David, P. A. (1985), Clio and the economics of QWERTY. American Economic Review, 75, 2, pp. 332-337.

Department of Health (2006), Our Health, Our Care, Our Say: A New Direction for Community Services, Cm 6737 (The Stationery Office).

Department of Health (2010), Equity and Excellence: Liberating the NHS (The Stationery Office).

Gillam, S. J., Siriwardena, A. N. and Steel, N. (2012), Pay-for-performance in the United Kingdom: impact of the quality and outcomes framework: a systematic review. Annals of Family Medicine, 10, 5, pp. 461-468.

Hannay, D. R., Usherwood, T. P. and Platts, M. (1992), Practice organization before and after the new contract: a survey of general practices in Sheffield. British Journal of General Practice, 42, 365, pp. 517-520.

Heins, E., Pollock, A. M. and Price, D. (2009), The commercialisation of GP services: a survey of APMS contracts and new GP ownership. British Journal of General Practice, 59, 567, pp. e339-e343.

Kaffash, J. and Matthews-King, A. (2015), GPs to be offered 'simplified' conditions under plans to tempt practices away from national contract. Pulse (www.pulsetoday.co.uk).

Lewis, J. (1997), Independent Contractors. GPs and the GP Contract in the Post-War Period (National Primary Care Research and Development Centre, Manchester)

Lewis, R. and Gillam, S. (2002), A fresh new contract for general practitioners. British Medical Journal, 324, 7345, pp. 1048-1049.

Lindblom, C. E. (1959), The science of muddling through. Public Administration Review, 19, 2, pp. 78-88.

Lindblom, C. E. (1979), Still muddling, not yet through. Public Administration Review, 39, 6, pp. 517-525.

Majeed, A., Rawaf, S. and De Maeseneer, J. (2012), Primary care in England: coping with financial austerity. British Journal of General
Practice, 62, 605, pp. 625-626.

McDermott, I., Checkland, K., Warwick-Giles, L. and Coleman, A. (2016), Understanding Primary Care Co-Commissioning: Uptake, Scope of Activity and Process of Change (Policy Research Unit in Commissioning and the Healthcare System, London).

NHS Commissioning Board (2012), Securing Excellence in Commissioning Primary Care.

NHS England (2014a), Annex F: Delegated commissioning model-draft terms of reference. Next Steps Towards Primary Care CoCommissioning.

NHS England (2014b), Next Steps Towards Primary Care Co-Commissioning.

NHS England (2014c), Review of PMS Contracts Gateway Ref. 01091.

NHS England (2015), Primary Care CoCommissioning Submission and Approval Process for 2015/16. Gateway Ref. 03515.

NHS England (2016a), The Forward View into Action: New Care Models: Update and Initial Support.

NHS England (2016b), The Multispecialty Community Provider (MCP) Emerging Care Model and Contract Framework.

Peckham, S. and Exworthy, M. (2003), Primary Care in the UK (Palgrave MacMillan).

Plsek, P. E. and Greenhalgh, T. (2001), Complexity science: the challenge of complexity in health care. British Medical Journal, 323, 7313, pp. 625-628.

Roughton, R. and Hakin, B. (2014) Letter to CCG Clinical Leads and Area Directors, NHS England: Co-Commissioning Of Primary Care Services (NHS England)

Schoen, C., Osborn, R., Doty, M. M., Bishop, M., Peugh, J. and Murukutla, N. (2007), Toward higher-performance health systems: adults' health care experiences in seven countries, 2007. Health Affairs, 26, 6, pp. w717-w734.

\section{IMPACT}

Policy-makers in England and internationally wrestle with planning and providing healthcare services in ways which improve outcomes and reduce costs. A strong primary care sector is an important asset, but it is not clear how best to achieve this. Our study of the impact of recent extensive changes to the English health system highlights the impossibility of fully predicting the consequences of such changes, and supports Lindblom's call for incremental policy adjustment. We show that, whatever funding mechanism is chosen, it is important that primary care service planning is decentralized to a regional organizational tier with detailed local knowledge. 
Shortell, S. M., Gillies, R. and Wu, F. (2010), United States innovations in health care delivery. Public Health Reviews, 32, 1, pp. 190212.

Sibbald, B., Bojke, C. and Gravelle, H. (2003), National survey of job satisfaction and retirement intentions among general practitioners in England. British Medical Journal, 326, 7379, p. 2.

Simon, H. A. (1984), Decision making and organizational design. In Pugh, D. S. (Ed), Organization Theory: Selected Writings, 2nd edn (Penguin Books).

Starfield, B., Shi, L. and Macinko, J. (2005), Contribution of primary care to health systems and health. Milbank Quarterly, 83, pp. 457-502.

Timmins, N. (2012), Never Again? The Story of the Health and Social Care Act 2012. A Study in
Coalition Government and Policy-Making (The King's Fund).

Tuohy, C. H. (1999), Accidental Logics: The Dynamics of Change in the Health Care Arena in the United States, Britain, and Canada (Oxford University Press).

Weiss, C. H. (1998), Evaluation (Prentice-Hall).

West, D. and Calkin, S. (2014), Revealed: NHS England's new area team structure. Health Service Journal (1 October).

Wilkin, D., Bjoke, C., Coleman, A. and Gravelle, H. (2004), The relationship between size and performance of primary care organizations in England. Journal of Health Services Research and Policy, 8, pp. 11-18.

World Health Organization (2008), The World Health Report 2008_Primary Health Care (Now More Than Ever). 